\title{
Constraints on the lamina density of laminar bone architecture of large-bodied dinosaurs and mammals
}

\author{
Rebecca Hofmann, Koen Stein, and P. Martin Sander \\ Acta Palaeontologica Polonica 59 (2), 2014: 287-294 doi: http://dx.doi.org/10.4202/app.2012.0149
}

Laminar bone tissue is commonly found in Dinosauria (including birds) and Mammalia. The tissue emerged convergently several times, and its frequent occurrence among amniotes has stimulated researchers to study some of its geometric features. One such feature is lamina thickness or lamina density (LD, expressed as number of laminae per $\mathrm{mm}$ ). We measured LD in a sample of sauropodomorph dinosaur taxa (basal sauropodomorphs, basal sauropods and Neosauropoda) and compared it with LD of a selection of mammals. LD is relatively constrained within the groups; nonetheless mean sauropodomorph LD differs significantly from mean mammal LD. However, increasing sample size with other dinosaur groups and more perissodactyls and artiodactyls may alter this result. Among sauropods, LD does not change drastically with increasing femur length although a slight tendency to decrease may be perceived. We conclude that the laminar vascular architecture is most likely determined by a combination of structural and functional as well as vascular supply and physiological causes.

Key words: Dinosauria, Mammalia, bone histology, laminar bone, lamina thickness, lamina density.

Rebecca Hofmann [rebecca hofmann@gmail.com] and P. Martin Sander [sander@uni-bonn.de ], Division of Paleontology, Steinmann Institute, University Bonn, Nussallee 8, 53113 Bonn, Germany; Koen Stein (corresponding author) [koen stein@yahoo.co.uk], Division of Paleontology, Steinmann Institute, University Bonn, Nussallee 8, 53113 Bonn, Germany; current address: Abteilung Forschung, Museum für Naturkunde, Leibniz-Institut für Evolutions- und Biodiversitätsforschung Invalidenstraße 43, 10115 Berlin.

This is an open-access article distributed under the terms of the Creative Commons Attribution License (for details please see creativecommons.org), which permits unrestricted use, distribution, and reproduction in any medium, provided the original author and source are credited. 
Farf Full text (296.7 kB) ।

For's Supplementary file $(95.7 \mathrm{kB})$ 